\title{
The use of CAD applications in the design of shredders for polymers
}

\author{
Marek Macko, ${ }^{1,}$, Krzysztof Tyszczuk ${ }^{1}$, Grzegorz Śmigielski ${ }^{1}$, Józef Flizikowski ${ }^{2}$, \\ Adam Mroziński ${ }^{2}$ \\ ${ }^{1}$ Faculty of Mathematics, Physics \& Technical Science, Kazimierz Wielki University in Bydgoszcz, Poland \\ ${ }^{2}$ Faculty of Mechanical Engineering, University of Technology and Life Sciences in Bydgoszcz, Poland
}

\begin{abstract}
Computer-aided design is now the primary design tool, providing opportunities for improving project quality, allowing for in-depth analysis of the specific features of the solution. In the methodology, computer simulation applications were used. Computer simulation aims to reconstruct the course of the studied process from its mathematical model using a computer and to examine the influence of the environment (input signals) and the internal properties of the object (process parameters) on the characteristics of the object. In designing the shredder, in addition to the selection of structural features, it is also possible to perform strength and kinematic simulations, resulting in a higher quality of the target solution. The results of the simulation work presented in the paper indicate a wide range of possible applications - also in the field of food engineering and processing of polymers - eg shredder mechanisms. Particular attention has been paid to the reduction of energy consumed by the deformation of samples, eg by pre-compaction of sample before introduction to the working area of the shredder. It has been estimated that the gap between the rotating discs should be minimized. Establishing design guidelines has resulted in a number of concept designs.
\end{abstract}

Keywords: CAD, Shredder, Simulation, Energy Efficiency

\section{Introduction}

The grinding is an important step in the preparation of the product, including food processing and plastics technology. This process is difficult to formal explanation because of the need to take into account the characteristics of random ways of cracking and movement of elements to be crushed in the workspace machines, changing boundary conditions load, etc. There are many papers describing CAD implementations in different applications and simulations $[1,2,3,4,5,6]$. In order to improve the efficiency of crushing undertaken numerous structural modifications and mechatronic implementations. They base on the use of modern systems of measurement and control in a chopper. With such implementations we can improve parameters using CAD tools as well as monitor parallel the grinding process, energy requirements as a measure of the energy required for grinding weight of $1 \mathrm{~kg}$ material [7,8]. For fine grinding, the unit energy requirement is between 20

*Corresponding author: mackomar@ukw.edu.pl

Reviewers: Milan Sága, Alžbeta Sapietová 
to $30 \mathrm{~kW} \cdot \mathrm{h} / \mathrm{Mg}$, and for very small increases up to $800 \mathrm{~kW} \cdot \mathrm{h} / \mathrm{Mg}$ (for current designs) [9, 10]. So high values are not conducive to lowering overall expenditures for shredding in both the manufacturing and the recycling of plastics. Energy demand for fragmentation is the greater, the smaller the average grain size after grinding. It is estimated that to achieve the grain size (product of grinding) - $10 \mathrm{~mm}$ requires $1 \mathrm{~kW} \cdot \mathrm{h} / \mathrm{Mg}$ (average value during grinding), while the disintegration to an average particle size of less than $1 \mathrm{~mm}$ need to 200 $\mathrm{kW} \cdot \mathrm{h} / \mathrm{Mg}$. Energy demand is related to design features shredder and implementation of mechatronic modules, e.g. the size of the gap between the knives (fixed and movable) decide on the level of demand for energy, but also affects the occurrence of dominant loads and deformations. For small size, the sample undergoes fracture gap $(1 \mathrm{~mm})$, and with increasing energy demand grows slot on fragmentation. For larger dimensions of the slot, pulling the material and its bending and disintegration.

The research includes implementation of CAD tools, especially in relations with geometric relations but also some simulations and mechatronic modules in laboratory/test stand in which the grinding process is employed to separate successive pieces of polymer materials as feed, by working the edge of the holes in the disks or drums [11]. Procedures of the solution of the problem as the mathematical procedure is an attempt to respond to the complexity of the creative process of inventing numerous strains of suboptimal design. The first attempts, supporting grinders, was carried out using desktops implemented the program IE_TEST-07_BIO. Power was very effective, but did not allow for mobile access to the program. There have been attempts to implement the program on e.g. mobile phones. The tests proved to be very fruitful and comfortable in co-operation for authors.

Laboratory tests shredding system implements many structural variants assemblies of shredder: drum, disc with holes cylindrical and polygonal disc with holes, selected on the basis of the matrix of possible solutions, filling the initial criteria for energy efficiency and grading curve. The experimental results expand the knowledge of the shredding and provide the material to the created and the staging database for the construction and the grinding process. These data were used in an integrated expert system in order to facilitate the selection of design shredder suitable materials. Additionally, the workspace chopper occurring complex processes of disintegration. The impact on the process of geometric features there are working elements, including shape, size, porosity shredded elements (related to their density) and a number of operating parameters that determine the behavior or degradation of intermolecular bonds, especially in the case of polymer materials. Susceptibility to grinding depends on the material properties, such as density, mechanical strength, durability, resistance to weather and environment active, thermal stability and electrical properties and thermal properties. The polymer materials are subject to physical and chemical changes that occur in the structure during processing, storage and use, which usually leads to deterioration of processability and performance. Rationalisation of factors affecting the properties of materials during their processing and use was considered in many publications [5].

Among the external factors, there are mentioned:

- climatic factors (eg. the atmospheric oxygen, water, air temperature, solar radiation, wind),

- environmental factors (corrosion, erosion, mechanical, biological),

- technical factors,

- process parameters (temperature, time, pressure),

- design features (plasticizing systems, tools and grinders),

- material (structure, shape, origin, pollution).

The largest percentage in the production of thermoplastic materials are polymers which when heated undergo plastic state and harden upon cooling while maintaining the ability to plasticize the next reheated. As a result, these materials can be processed hot and repeatedly formed. It is also possible the processing of post-consumer waste. 
In the area of design shredders, it is richly represented achievements on the knife mills, including shredders with variety of geometrical relations. Requirements for shredding plastics inspire the search for new - alternative design solutions. There are known constructional solutions for special polymer materials and shredders for a wide range of design solutions and performance measured in $\mathrm{kg} / \mathrm{hr}$. Among the industrial design solutions there are well known cylindrical grinders, breakers, crushers, ball mills, vibrating rod and knife grinders with specific geometrical features, put into production (including IMPB Torun, TRYMET Pilchowo, Instalwent Bydgoszcz, Heinrich Dreher GmbH \& Co. KG Hellweg Maschinenbau GmbH \& Co. KG, Weima, Hosokawa Alpine and many others).

\section{CAD and mechatronic implementations}

Interdisciplinary, especially mechatronic aspects of our work, use advanced computer techniques especially $\mathrm{CAD} / \mathrm{CAE}$ and $\mathrm{AI}$, which in combination with the achievements in the field of mechanical engineering and robotics contribute to the improvement of product quality (especially in the area of materials engineering). Innovative shredding system is based on the applications and intelligent procedures that could ultimately improve the efficiency of the processes taking place in the overall loop recycling and shredding for preparing materials for further processing. It contains a high potential for dissemination of commercial, as it could be (in the future) easy to use, particularly in small and mediumsized enterprises, which dominate the regional environment, polymer processing.

Work goals can be achieved through the implementation of the proposed research methodology, which include research in several areas:

A. Development of the knowledge about the shredding and granulation of specialized systems, design, material properties (polymers, organic materials), some of the relationships between process parameters and design of the grinding system. The choice of design grinder (multi knife edge and grinders) and prepare a 3D virtual model (in SolidWorks) to strength and kinematics simulation

B. Model feedback operation on the basis of image analysis grinding device. At this stage neural network application has been used to recognize the size of the granules and analysis to design features of the grinders which are responsible for improving the condition.

To identify and assess properties of grinding products based on selected multi-edge grinding technologies in recycling, the following design solutions (from the allowable set) were assumed: which maximize (efficiency, output, degree of fineness) or minimize (power demand, unit energy consumption, energy dissipation, torque, angular, linear and rotational speed) values of selected operational characteristics.

Integrated system allows determining permissible range of variables (design properties) of the grinder in laboratory circumstances thanks to used computer aided experiment, design and operation of grinders. To allow objective assessment of the efficiency, authors used the measuring system that features recording of momentary values of torque and momentary values of rotational speed of the drive shaft (fig. 1, fig. 2). The test station was designed to allow replacement of the working assembly (knife-, disk- or beater system) as well as change of orientation (from horizontal to vertical). 


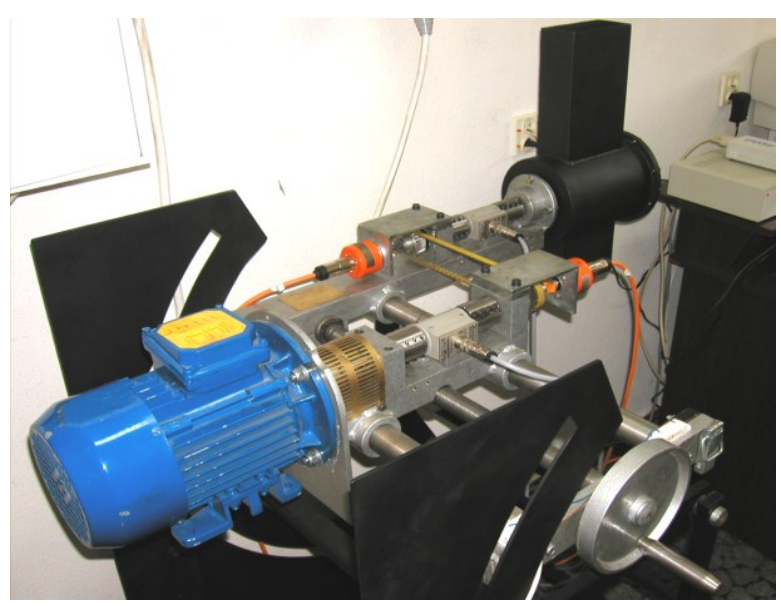

Fig. 1. General view of a laboratory research stand shredding

Similar like other complex technological processes, the grinding depends on many factors that can be classified into system and design related factors (associated with grinding assembly and its equipment) and process-related factors.

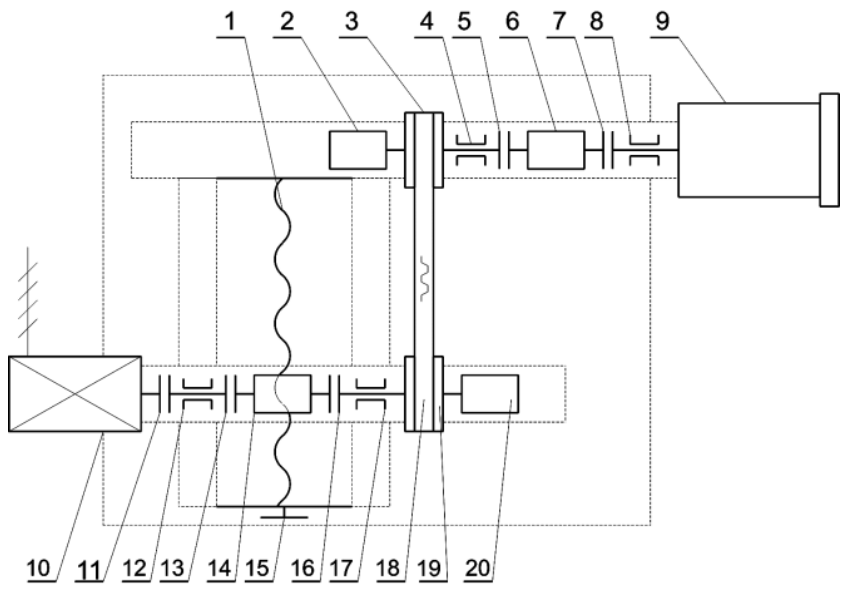

Fig. 2. Diagram of the mechanical/laboratory research stand shredding ULR-2.0/2004: 1 - screw for adjusting the distance between the motor shaft and chopper, 2 - rotary transducer - Pulse, 3 - wheel gear-toothed in strips, 4 - radial bearing, 5 - clutch splints, 6 - measuring shaft, 7 - clutch splints, 8 - radial bearing, 9 - chamber grinder, 10 - engine, 11 - clutch splints, 12 - radial bearing, 13 - clutch splints, 15 - measuring shaft, 16 - clutch splints, 17 - radial bearing, 18 - a toothed belt transmission, 19 - gear wheel in strips-gear, 20 - rotary transducer

The first group of factors includes: applied grinding system (of periodical, continuous or periodically-cyclic type), number of grinding machines and their grouping, the system of connections between grinders and plasticizing equipment as well as characteristics of applied equipment (sort, type, peripheral speed, grinding components and their design properties etc.).The modular system includes a grinding expanded module to control the speed controller of management, the chamber for grinding, moisture sensors, computer chip, charge sensor and an extensive application that manages the system (Fig. 3). 


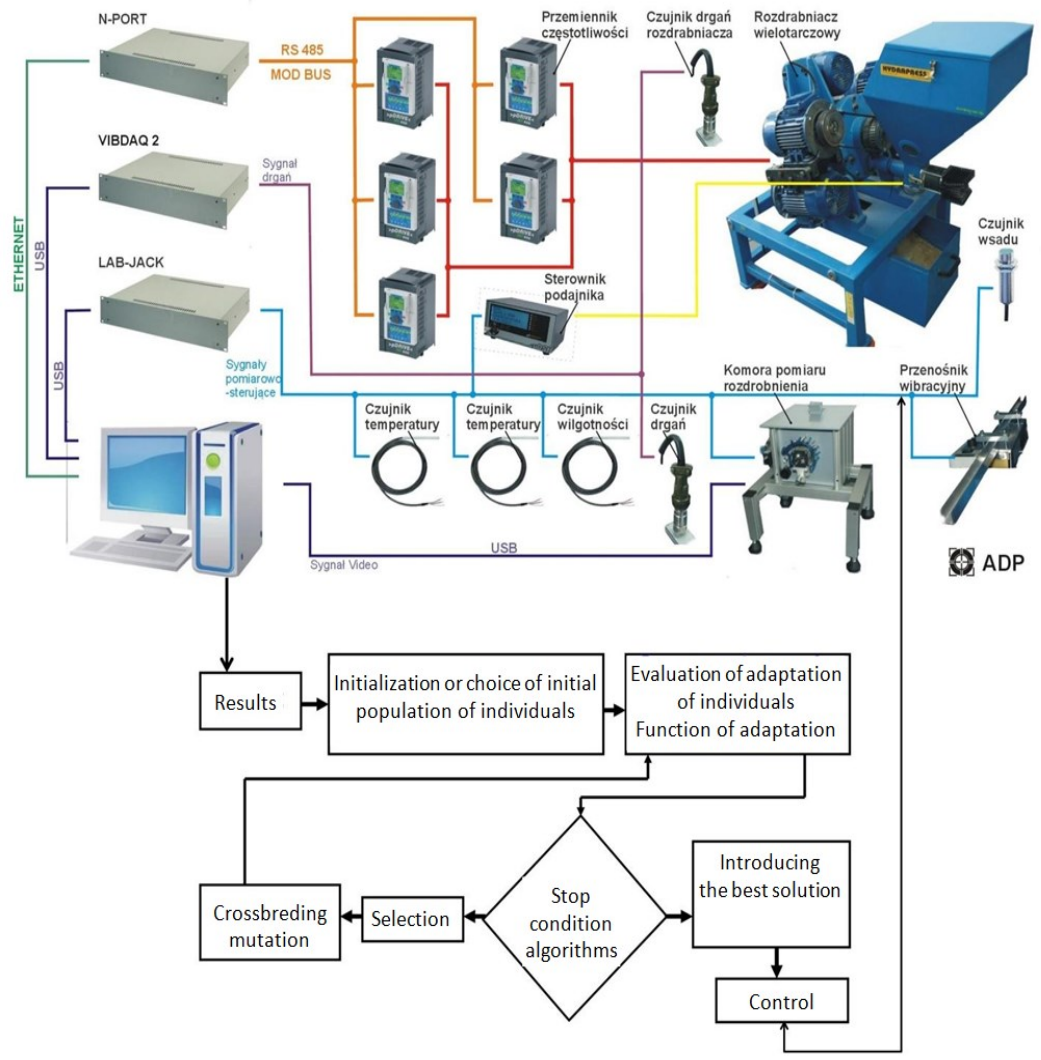

Fig. 3. Modular - mechatronic system of shredding

The computer monitor shows the dynamic characteristics of the grinding process, energy demand, the measurement of particles of particulate material (fig. 4).

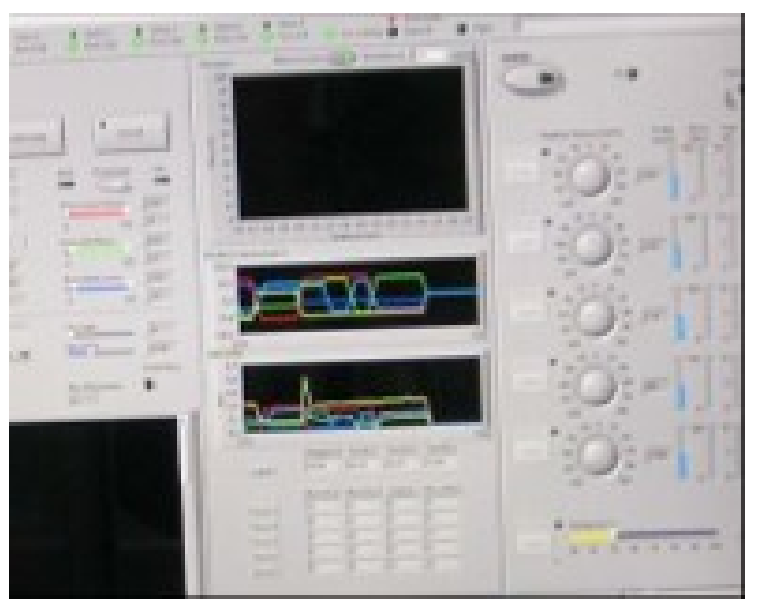

Fig. 4. The screen of research shredder based of multi-disc, RWT- 5KZ, active screen control system 


\section{Results}

The purpose of the model is to determine the decision-making LabVIEW shares to be applied to an object. This module is based on current measurements collected from sensors and experience (stored in the knowledge module) determines decisions. They are sent to the executive module and learner. The module shall send decisions to the object, while learners take account of decisions in the learning process for the subsequent assessment of the effects of the decision. The main challenge for system designers is to create algorithms that can make the correct decisions in the case of incomplete or redundant information.

Each time you launch the experiment generates the report as a file in the .xls format. The files are placed in the directory My_documents/Mill/AG/ (fig. 5). The file names contain the date, hour and minute of the start of the experiment.

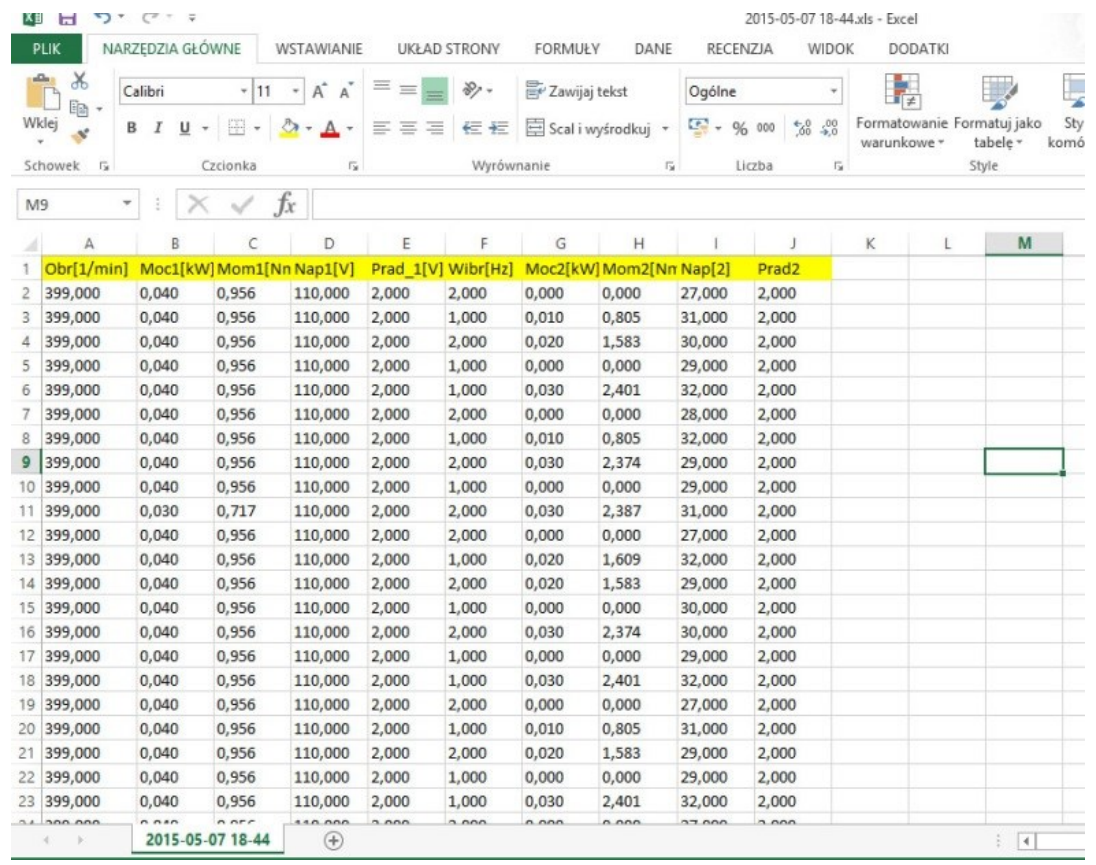

Fig. 5. Example registered in the disk file the results of measurement of the efficiency of the powertrain grinder (mill rotary vibration) [9].

The task of the executive module is to provide the control signal (designated by the decision module) to an object, for example. Settings update drives. Due to the changing conditions of grinding (change in weight of the stock, the phenomenon related to the change of humidity, e.g. unstabilized grains), it is necessary to use the adaptive formulating optimal conditions and changes actuators, set the speed of dosing, the angular velocity of each target (usually being a function of humidity, form and grain size) for the current state variable processing. The auto-monitor includes monitoring sensors: speed, acceleration, force and torque, the form and dimensions of the product; drivers, so you can make the switching characteristics of the performance; photo-optical systems, electronic counting modulation and demodulation, amplification, switching signals, comparison and logical operations control, regulation, compensation.

The genetic algorithm used in the default configuration, testing 34 combinations of settings of the drive. Amount of the combination has been adapted to the size of the tray 
material for grinding process speed so that one of the feed provided to carry out the experiment.

The results of experimental studies broaden the knowledge of shredding and provide the material for the staging created and the current database structure and the multi-holes grinding process. These data were used in integrated expert system to facilitate the selection of construction shredder suitable materials.

The concept of laboratory enables the experimental grinding for a wide range of factors constant:

- material properties and shape of the shredded as feed,

- dimensions of shredded,

- and variables.

\section{Conclusions}

Engineering of shredding, cognitively active monitoring industrial processing IPP is an issue the vast and emerging on the basis of fragmentary experience of technical sciences and cognitive science achievement. In designing future monitors, intelligent systems based on cognitive science, we can not forget about the use of classical control theory, which is indispensable in issues related to stability and resistance - the security processing in general.

Developed mathematical apparatus, methods of analysis and synthesis of structures regulating the loop feedback modeling algorithms and identification, theory of stability, theory of optimality - all these issues are part of the field, which is the control theory.

It is not possible to develop the concept of mechatronic systems shredding, cognitively active monitoring, apart from classical control theory. Classical control theory man, should play a leading role in the development of future advanced systems, because only in this way can be the condition of safety, that is, for control systems, regulation and compensation objectives and conditions for the industrial processing, basic. Positively verified assumptions and solved the problem of self-regulation, to obtain a product with the specified geometric dimensions in the process with minimal power requirements, rational efficiency (minimum energy consumption per unit, in a special integrated circuit grinding cereal grains.

Usefulness of the mechatronic laboratory set-up gives results for wide variety of geometric features and exploitation parameters (e.g. power consumption). Proposal of a design of shredder with maximum possible efficiency is reduced primarily to finding a design of the grinding assembly and of the machine that is specific to a given material, making it possible to obtain a desired product, and to selection of process variables ensuring minimum energy expenditure in combination with rational shredding efficiency.

Purpose of the development, which consists in designing and implementing modern computer-aided research subsystems: process efficiency, product quality, harmlessness of the product and the grinding process of high complexity has been achieved. Solved the problem of measurement, collection and analysis of the characteristics of utility, state postulated grinding. Collection, analysis and processing of data on the state indicators are based on computer support in an environment of LabVIEW. The measurement system supports the position of the grinding technology: precision (RPW-11NT), rotationally vibrating (lm-S2n2x2) sześciowalcowego (ZBPP-6W), multi-plate (RWT-7JA). Besides designating the characteristics of utility lets you explore, develop, apply and explore ideas and structures, technologies of grinding, grinding. The essence of the technical system, including the system of measuring shredding is to ensure the efficient flow of data in the shredding and adequate procedures to achieve the assumed level of knowledge of the entire technical system, in the context of specified development needs, innovation and progress. 
Processing of biological materials (eg. Grain, feed, food), polymeric materials, suitable defined goals cognition takes into account the specific characteristics of the material being processed, machine design and parameters of the grinding process.

\section{References}

1. M. Sága, M. Vaško, P. Pecháč, Chosen Numerical Algorithms for Interval Finite Element Analysis. Procedia Engineering 96, 400-409 (2014)

2. M. Vaško, M. Sága, Application of Fuzzy Structural Analysis for Damage Prediction Considering Uncertain S/N Curve. Applied Mechanics and Materials 420, 21-29 (2013)

3. P. Pecháč, M. Sága, Controlling of Local search Methods' Parameters in Memetic Algorithms Using the Principles of Simulated Annealing. Procedia Engineering 136, 70-76 (2016)

4. G. Domek, M. Dudziak, Energy Dissipation in Timing Belts Made from Composite Materials. Advanced Materials Research, 189-193 (2011)

5. E. Rusiński, P. Moczko, D. Pietrusiak, G. Przybyłek, Experimental and numerical studies of jaw crusher supporting structure fatigue failure. Strojniški vestnik - Journal of Mechanical Engineering 59 9, (2013)

6. E. Rusiński, J. Czmochowski, D. Pietrusiak, Selected Problems in Designing and Constructing Surface Mining Machinery. FME Transactions 40 (4), (2012)

7. Czerniak J.M., Macko M., Ewald D.: The CutMAG as a new hybrid method for multiedge grinder design optimisation. Advances in Intelligent Systems and Computing 401, 327-337 (2016)

8. J. Flizikowski, A. Mrozinski, K. Dziadosz, Modelling of multi discs grain grinders constructions. CHISA 2006 - 17th Int. Congress of Chem. and Proc. Eng.

9. J. Flizikowski, A. Mroziński, A. Tomporowski, Active monitoring as cognitive control of grinders design. AIP Conference Proceedings 1822, 020006, (2017)

10. A. Tomporowski, J. Flizikowski, Motion characteristics of a multi-disc grinder of biomass grain. PRZEMYSŁ CHEMICZNY 92, 498-503 (2013)

11. M. Macko, Metoda doboru rozdrabniaczy wielokrawędziowych do przeróbki materiałów polimerowych. Wyd.UKW, Bydgoszcz, (2011) 